\title{
Carbon transport, deposition and fuel accumulation in castellated structures exposed in TEXTOR
}

\author{
A. Litnovsky ${ }^{\text {a,* }}$, V. Philipps ${ }^{\text {a }}$, A. Kirschner ${ }^{\text {a }}$, P. Wienhold ${ }^{\text {a }}$, G. Sergienko ${ }^{\text {a }}$, \\ A. Kreter ${ }^{\text {a }}$, U. Samm ${ }^{\text {a }}$, O. Schmitz ${ }^{\text {a }}$, K. Krieger ${ }^{\text {b }}$, P. Karduck ${ }^{\text {c }}$, \\ M. Blome ${ }^{c}$, B. Emmoth ${ }^{d}$, M. Rubel ${ }^{\text {e }}$, U. Breuer ${ }^{\text {f }}$, A. Scholl ${ }^{\mathrm{f}}$ \\ ${ }^{a}$ Institut für Plasmaphysik, Association EURATOM, TEC, FZ-Jülich, Germany \\ b Association EURATOM, Max-Planck-Institut für Plasmaphysik, Garching, Germany \\ ${ }^{\mathrm{c}}$ Herzogenrather Dienstleistungszentrum GbR, Herzogenrath, Germany \\ ${ }^{\mathrm{d}}$ Department of Microelectronics, KTH, Association EURATOM - VR, Kista, Sweden \\ e Alfvén Laboratory, KTH, Association EURATOM - VR, Stockholm, Sweden \\ f Zentralabteilung fur Chemische Analysen, FZ-Jülich, Germany
}

\begin{abstract}
In order to maintain the thermo-mechanical durability of ITER it is proposed to castellate the interior surface of the first wall and divertor by splitting them into small-size cells [W. Daener et al., Fusion Eng. Des. 61\&62 (2002) 61]. A concern is the accumulation of fuel in the gaps of the castellation. In TEXTOR, molybdenum limiters were exposed in the scrape-off layer (SOL) plasma to assess fuel accumulation. The first limiter was exposed under deposition-dominated conditions. Carbon deposits were formed both on top surfaces and in the gaps. About $0.12 \%$ of the impinging D-fluence was found in the gaps. Another castellated limiter was exposed under erosion-dominated conditions. Deposited layers were found only on the plasma shadowed areas of the gaps. A significant amount of molybdenum from the limiter was found intermixed in the deposit. The gaps contained $\sim 0.03 \%$ of the impinging D-fluence. Modeling was performed to simulate carbon transport into the gaps.
\end{abstract}

(c) 2007 Elsevier B.V. All rights reserved.

PACS: 52.55.Fa; 52.40.Hf; 52.25.Vy

\section{Introduction}

The plasma facing components of a first wall and divertor in ITER have to withstand a severe radiation environment with intensive particle and heat

\footnotetext{
* Corresponding author. Fax: +49 2461612660.

E-mail address: a.litnovsky@fz-juelich.de (A. Litnovsky).
}

loads. To provide thermo-mechanical stability, it has been proposed to split the armor of the interior into small-size cells [1]. However, there is a concern that the impurity deposition and fuel accumulation will occur in the gaps of the castellation. Results available from JET, DIII-D and TFTR may imply an unacceptable level of fuel accumulation in ITER [2-6]. Finding an effective way to remove the deposits represents a challenging task [7]. 
The understanding of impurity deposition and the underlying physical phenomena are of crucial importance. Dedicated experiments made with an ITER-like castellation geometry, can provide an effective way to address these questions. Such experiments are presently ongoing on TEXTOR, ASDEX-Upgrade, DIII-D and Tore-Supra.

In TEXTOR, metallic limiters with ITER-like castellation were exposed in the SOL plasma. In the first experiment, the limiter was exposed under deposition-dominated conditions. Another castellated limiter was subject to the net erosion environment. These two experiments were intended to approach the environment expected near the vertical target (VT) of ITER away from the strike zones and close to them, respectively. The experiments were intended to complement each other in an attempt to address the variety of processes in ITER divertor.

\section{Exposure of castellated limiters in the SOL plasma of TEXTOR}

The design of castellated limiters used in the experiments is described in detail in [8]. The castellated structure consisted of 8 rows with 6 cells each with gaps of $0.5 \mathrm{~mm}$ between them. The dimensions of cells were $10 \times 10 \times 10 \mathrm{~mm}$. The castellation was fabricated from TZM alloy consisting of 99 at.\% Mo, 0.5 at. $\% \mathrm{Zr}$ and 0.1 at.\% Ti. For the limiter exposed in the erosion-dominated conditions the first row of castellation was made from graphite.

For simplicity, we will name exposures made in the deposition-dominated and erosion-dominated conditions as 'Deposition' and 'Erosion' experiments, respectively. We will introduce the nomenclature to identify the cells of castellation and sides of gaps as shown in Fig. 1.

For the deposition experiment, the limiter was exposed at a radial distance $R=48.5 \mathrm{~cm}$ from plasma center and $2.5 \mathrm{~cm}$ behind the last close flux surface (LCFS) during 125 plasma discharges with a total duration of 559 plasma seconds. The discharges were mixed NBI-, ECR- and ICR-heated discharges with varying power as described in [8]. The line-averaged central density was within (1.55) $\times 10^{13} \mathrm{~cm}^{-3}$ during the exposure. The ion fluence on the limiter estimated using He-beam data had a value of $4.9 \times 10^{19}$ ion $/ \mathrm{cm}^{2}$ averaged over the area of castellation. The surface temperature of the limiter was varied from $200{ }^{\circ} \mathrm{C}$ to $400{ }^{\circ} \mathrm{C}$ which agrees
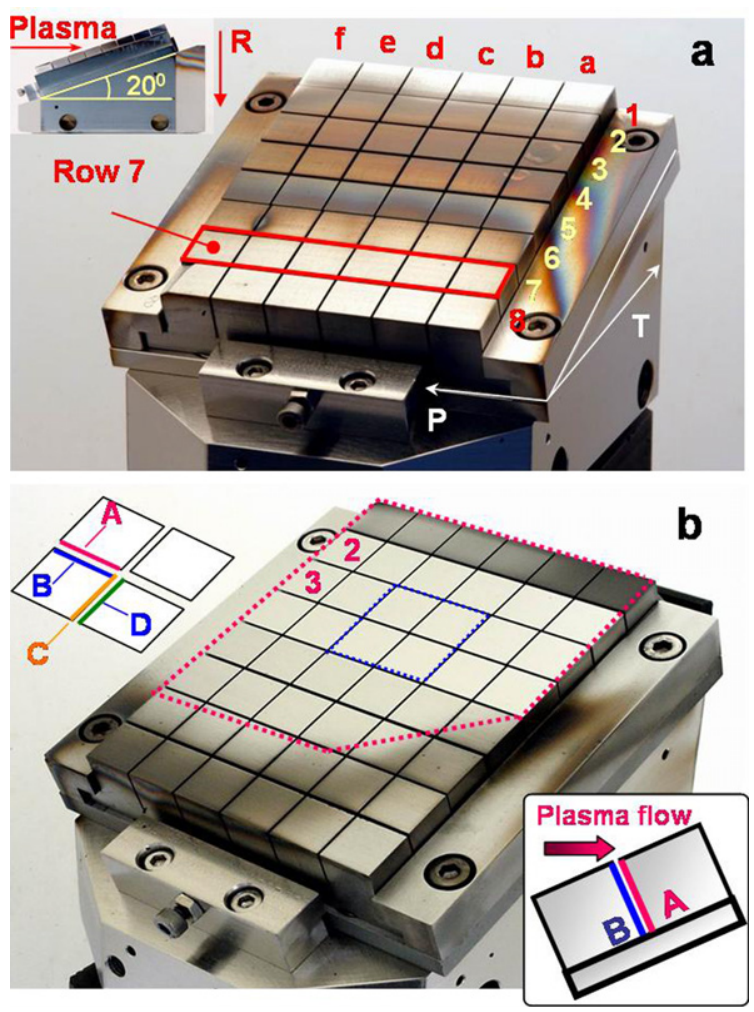

Fig. 1. General view of castellated limiter exposed in (a) deposition conditions and (b) erosion conditions. $P$ and $T$ and $R$ stand for poloidal, toroidal and radial directions, respectively. 1-8 are the rows of castellation, a-f are the segments. A, B, C, D are the sides of gaps.

well with values expected for upper vertical targets of ITER divertor [9].

For the erosion experiment, the second limiter was exposed at a radial distance $R=47.3 \mathrm{~cm}$ from plasma center and $1.3 \mathrm{~cm}$ behind the LCFS. Thirty nine identical NBI-heated discharges were carried out for a total exposure duration of 219 plasma seconds. The line-averaged central plasma density was $(3-3.5) \times 10^{13} \mathrm{~cm}^{-3}$. The temperature of the bulk of the limiter was within $220-300{ }^{\circ} \mathrm{C}$ as measured by thermocouples. Surface temperature was monitored with optical pyrometers and rose from $300{ }^{\circ} \mathrm{C}$ up to $430{ }^{\circ} \mathrm{C}$ during the discharge. Excursions of the surface temperature at the leading edge of castellation up to $1850{ }^{\circ} \mathrm{C}$ were observed for $1-1.5 \mathrm{~s}$ in a few shots due to plasma shifts. Electron temperature and density were measured with a helium beam diagnostic. Total averaged fluence received by the castellated structure was $\sim 2 \times 10^{20}$ ion $/ \mathrm{cm}^{2}$ which is approximately 4 times more than the fluence accumulated during the deposition experiment. 
During the exposures, the castellation was inclined at an angle of $20^{\circ}$ with respect to the toroidal field direction as shown in Fig. 1.

\section{Analyses of the deposited layers after exposures}

For the limiter exposed in the deposition experiment a transition from net erosion on areas nearest to the plasma to net deposition deeper in the SOL was observed on the top surface. A maximum of deposition film thickness of about $350 \mathrm{~nm}$ was estimated by analysis of the interference colors [10].

After dismantling the limiter, deposited layers were found in the poloidal gaps located on a stripe-like area with a width of $1-1.5 \mathrm{~mm}$ at the plasma-closest edges, as shown in Fig. 2(a). A film thickness of $\sim 100 \mathrm{~nm}$ was detected on these gaps [8].

The limiter exposed in the erosion experiment is shown in Fig. 1(b). Plasma facing surfaces on the top of the structure were metallically shiny, unlike in the previous experiment. After disassembly of the limiter, deposits were found in the castellation gaps as presented in Fig. 2(b). Two different deposition patterns occurred on the sides of the gaps depending on their orientation with respect to the impinging plasma flux: plasma facing sides (side A, Fig. 2(c)) and sides, shadowed from plasma (side B, Fig. 2(d)). Narrow shiny areas were found on the plasma facing sides in the areas of gaps directly exposed to plasma. These areas were absent on the plasma shadowed sides of the gaps. On the limiter exposed in the deposition experiment, only patterns similar to those shown in Fig. 2(d) were observed.

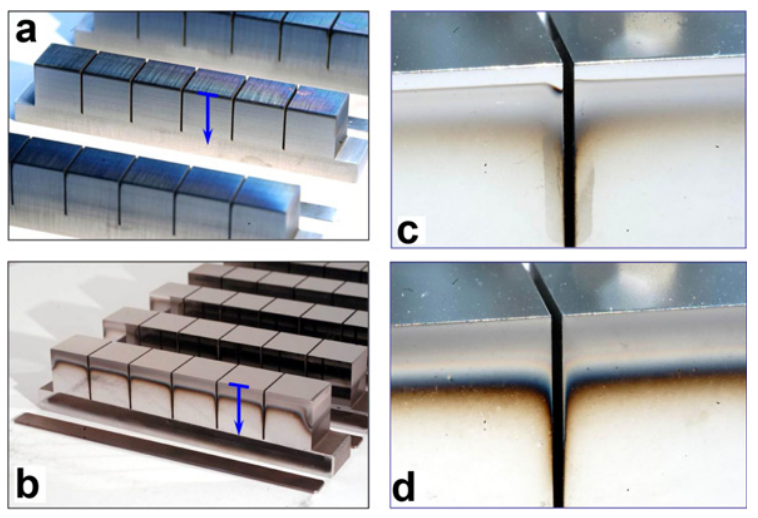

Fig. 2. Photos of gaps (a) from the deposition experiment, (b) from the erosion experiment, (c) erosion experiment, plasma open side A, (d) erosion experiment, plasma shadowed side B. Arrows show the locations of line scans with EDX, WDX and EPMA.
To characterize the elemental content of deposits, secondary ion mass spectrometry (SIMS) measurements were made on both plasma facing top surfaces and in the gaps of both limiters by applying a $2 \mathrm{keV}$ Cs-beam as a sputtering beam, and a $25 \mathrm{keV}$ Ga-beam for timing. SIMS measurements were calibrated using a reference ellipsometrically pre-characterized sample and stylus depth profiling of the SIMS crater, so that sputter speed was known with an accuracy of $20 \%$.

SIMS analysis of the limiter exposed in deposition-dominated conditions has proven that the deposit is a carbon film containing $\mathrm{H}, \mathrm{D}, \mathrm{O}$ and B. SIMS results from this limiter are presented in Fig. 3(a), showing the comparison of the deposited film thickness measured on the top surfaces of rows 2 and 3 and in the gap located on row 2 side A.

As expected for the limiter exposed in the erosion experiment, no deposits were found on the top surfaces in the area of net erosion. No deposits were
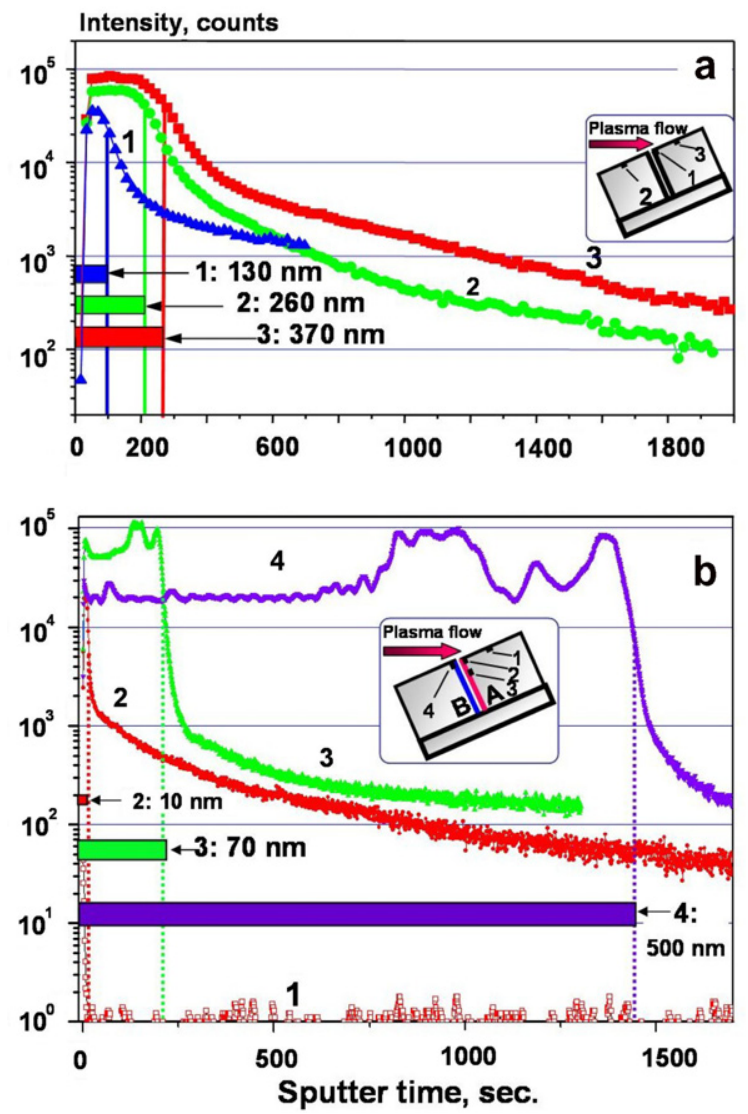

Fig. 3. Depth profiling of the deposited layers by SIMS: (a) for the deposition experiment and (b) for the erosion experiment. Intensity of ${ }^{12} \mathrm{C}$ signal is shown. 
either detected on the shiny areas of plasma open gaps directly exposed to plasma. This supports the idea that these areas were areas of net erosion. Deposits with a thickness of up to $100 \mathrm{~nm}$ were detected just below the shiny area, on the plasma open sides (side A, Fig. 2(c)). In contrast, on the plasma shadowed sides of gaps (side B, Fig. 2(d)), a deposit thickness of $\sim 0.5 \mu \mathrm{m}$ was measured at the distance of $0.5 \mathrm{~mm}$ from the plasma-closest edge. An example of SIMS measurements made on top of rows 2 and 3 and in the gap between these rows is given in Fig. 3(b) along with deposit thickness estimates.

To determine the distribution of the deposit thickness along the depth of the gaps, energy dispersive X-ray spectroscopy (EDX), wavelength-dispersive X-ray spectroscopy (WDX) and electron probe microanalysis (EPMA) measurements were made.

For the limiter exposed in the deposition experiment, the measurements are described in [8]. An example of the EDX spectra is shown in Fig. 4(a). The data show a decrease of the deposited layer
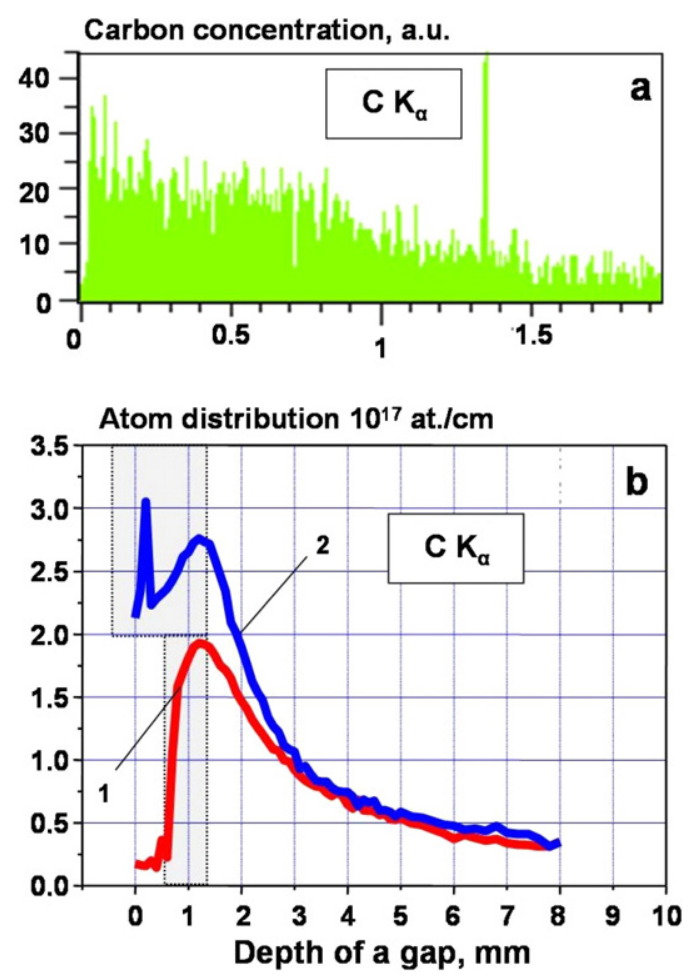

Fig. 4. EDX/WDX and EPMA investigations in the gaps of castellated limiters (a) for the deposition experiment, carbon content: $\mathrm{K}_{\alpha}$ line scanned, (b) from erosion experiment, carbon content: (1) plasma-facing side of a gap (Fig. 1b, side A); (2) plasma-shadowed side of a gap (Fig. 1b, side B). $\mathrm{K}_{\alpha}$ line scanned. thickness in the gaps, with a decay length of about $1.5-1.7 \mathrm{~mm}$.

For the limiter exposed in the erosion experiment, EPMA scans were made along the depth of the gaps as shown in Fig. 4(b). As inferred from EPMA measurements, the deposit thickness decreases exponentially with gap depth with an efolding length of about $1.7-2 \mathrm{~mm}$, similar to the deposition experiment.

EPMA and SIMS measurements made on the limiter exposed in the erosion experiment revealed the presence of molybdenum released from the castellation and intermixed into the deposited layers. Modeling was performed to estimate the amount of molybdenum in the deposit. The intensity of Xray radiation from the sample detected during EPMA measurements was simulated for a known deposit thickness by varying the molybdenum content in the deposit. The best fit to the experimental data was obtained by assuming that the deposit contains at least 65 at. $\%$ of molybdenum.

\section{Fuel inventory in gaps}

Nuclear reaction analysis (NRA) investigations were carried out to estimate the total deuterium content. Measurements were done with a $1.2 \mathrm{MeV}$ ${ }^{3} \mathrm{He}^{+}$beam using the nuclear reaction $\left[{ }^{3} \mathrm{He}(\mathrm{d}, \mathrm{p}){ }^{4} \mathrm{He}\right]$ on both the top surfaces and in the gaps on both limiters.

For the limiter exposed under deposition conditions, the average concentration on the top surfaces of row 4 was found to be $1.7 \times 10^{17} \mathrm{D} / \mathrm{cm}^{2}$ and around $1.0 \times 10^{17} \mathrm{D} / \mathrm{cm}^{2}$ in the poloidal gaps of the row 3, side B. Combining NRA and SIMS results, a $\mathrm{D} / \mathrm{C}$ ratio of approximately 0.11 for top surfaces and 0.13 for poloidal gaps is found. However, TEXTOR was operated during the exposure with a mixture of $\mathrm{H}$ and $\mathrm{D}$ in plasmas with a ratio of $\mathrm{H}: \mathrm{D} \sim 1: 1$ [8]. Thus, the overall $(\mathrm{H}+\mathrm{D}) / \mathrm{C}$ ratio is about 0.2 . As estimated from NRA measurements [8], about $0.12 \%$ of impinging $(\mathrm{D}+\mathrm{H})$-fluence is stored in the gaps.

NRA measurements were made on several locations in toroidal gaps after breaking the limiter. High areal $\mathrm{D}$ concentrations in the range of (47) $\times 10^{17} \mathrm{D} / \mathrm{cm}^{2}$ were measured. However, further investigations are needed to make firm conclusions on deposition in toroidal gaps. This will be addressed in forthcoming experiments in TEXTOR.

For the limiter exposed in erosion conditions, the amount of $\mathrm{D}$ fuel in the gaps of rows 2 and 3 was 
measured to be $(5-10) \times 10^{16} \mathrm{D} / \mathrm{cm}^{2}$, whereas on top surfaces the $\mathrm{D}$ amount was at or below the measurable limit: $\sim 1 \times 10^{15} \mathrm{D} / \mathrm{cm}^{2}$. D/C ratio was varying between 0.01 and 0.1 . The fuel pattern along the depth of a gap exhibited a double exponential decay with $\lambda_{\mathrm{D} 1} \sim 1 \mathrm{~mm}$ for the plasma-closest first $4 \mathrm{~mm}$ of a gap and $\lambda_{\mathrm{D} 2} \sim 4 \mathrm{~mm}$ deeper in the gap. The amount of $\mathrm{D}$ in gaps was estimated to be about $0.03 \%$ of the total fluence impinging on castellation.

\section{Modeling of the deposition patterns}

The modeling of the carbon transport in remote areas was performed earlier for pump-duct systems and areas below the divertor $[11,12]$. First attempts were made to model the deposition patterns in the gaps of the limiter exposed in erosion conditions using a similar model as in [11]. The entire gap was split into 41 segments starting from the plasma closest shadowed edge as it is shown in Fig. 5. A local recycling carbon source was introduced on the uppermost part of plasma open side of the gap (cell 41) and 30000 neutral particles were launched from it. The recycled particle flux had a cosine distribution with respect to the impinging plasma flow. For the first runs only carbon reflection from the molybdenum substrate was modeled with varying reflection coefficients $R: 0.0,0.1,0.5$ and 0.9 . The results of modeling were compared with normalized data from SIMS and EPMA analyses as presented in Fig. 5. The approximation of a simple particle reflection from the sides of gaps i.e. 'ping-pong transport' with fixed reflection coefficient coincided well with experimental data assuming a reflection

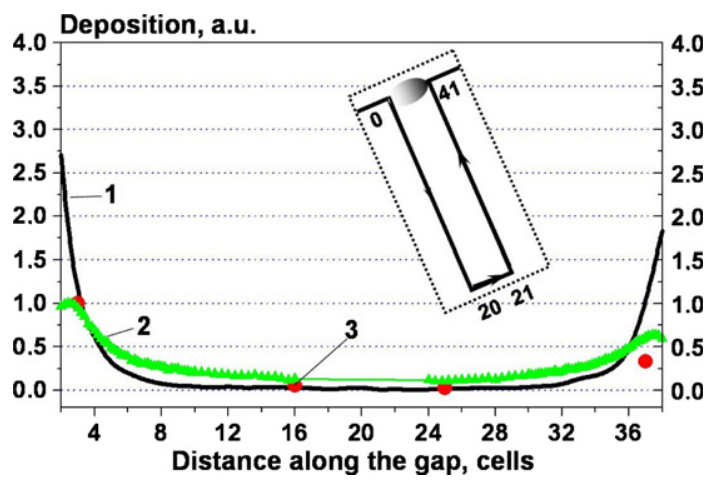

Fig. 5. The results of the first modeling patterns: (1) simulation results: data for reflection coefficient $R=0.5$ is plotted; (2) normalized data from SIMS; (3) normalized data from EPMA measurements. coefficient $R=0.5$. This outlines the importance of reflection processes in assessing deposition in gaps. Modeling predicts the thickest deposits on the uppermost parts of the gaps, with the exception of the zone of local erosion. However, more experimental data for these locations is needed to allow a reliable comparison and the dedicated measurements are underway.

\section{Summary and conclusions}

Two castellated limiters with an ITER-like geometry were exposed in the deposition and erosiondominated conditions in the SOL of TEXTOR.

After the exposures, deposits were found both on the top surfaces and in the gaps for the limiter exposed in deposition-dominated conditions. For the limiter exposed in erosion conditions, top surfaces were clean and deposits were found in gaps only. Generally, the thickness of deposited layers on both limiters represents an exponential decay with a characteristic e-folding length of $1.2-1.7 \mathrm{~mm}$. These findings correlate with the results from the other machines [13] which demonstrate the common nature of deposition processes in gaps.

The elemental composition of deposits on the two limiters was different. For the limiter exposed in deposition experiment, carbon layers containing $\mathrm{H}, \mathrm{D}, \mathrm{C}, \mathrm{B}, \mathrm{O}$ were formed whereas massive metal intermixing was detected in the gaps of the limiter exposed to erosion conditions. The molybdenum content in the deposit was at least 65 at.\%. The molybdenum originates from the local erosion on the plasma open side of the gap.

The amount of fuel accumulated in gaps of the limiter exposed in deposition conditions was estimated to be $0.12 \%$ of the impinging plasma fluence. For the limiter exposed in erosion conditions this fraction was lower: $\sim 0.03 \%$. This may be due to a higher base temperature and thermal excursions for this limiter during exposure. Fuel content in the toroidal gaps of the limiter exposed under deposition conditions was found to be higher than the fuel amount in poloidal gaps. A similar pattern was observed in ASDEX-Upgrade [13], showing that the alignment of gaps with respect to the magnetic field is an important parameter. Another effect of the field geometry is the strong re-erosion observed on the areas where the gap edge is directly facing the incident field lines. The re-eroded material is predominantly found at the opposite sides shaded from direct field line incidence. 
An attempt was made to model the deposition patterns in gaps. Good agreement of modeling results with experimental data was achieved by assuming a particle reflection coefficient of 0.5 for carbon atoms trapped in gaps. This outlines the importance of reflection while assessing the processes in gaps. However, more experimental data on the edges of gaps are needed to allow a better comparison with modeling.

\section{Acknowledgements}

The authors would like to express their gratitude to Dr B. Schweer, H. Reimer, M. Freisinger, K. von Bovert and TEXTOR team. We are grateful to Dr J. Linke and Dr E. Wessel (IWV 2, FZ Jülich) for the electron beam diagnostics and fruitful discussions. This work is being made within the research pro- gram of the European Task Force on Plasma-Wall interactions.

\section{References}

[1] W. Daener et al., Fus. Eng. Des. 61\&62 (2002) 61.

[2] D.G. Whyte et al., Nucl. Fus. 39 (8) (1999) 1025.

[3] W.L. Hsu et al., J. Vac. Sci. Technol. A 7 (1989) 1065.

[4] D. Walsh et al., J. Vac. Sci. Technol. A 10 (1992) 1174.

[5] C.H. Skinner, Nucl. Fus. 39 (1999) 271.

[6] M. Rubel et al., Phys. Scr. T111 (2004) 112.

[7] P.L. Andrew et al., Fus. Eng. Des. 47 (1999) 233.

[8] A. Litnovsky et al., J. Nucl. Mater. 337-339 (2005) 917.

[9] J. Roth et al., J. Nucl. Mater. 337-339 (2005) 970.

[10] P. Wienhold, F. Weschenfelder, J. Winter, Nucl. Instrum. and Meth. B 94 (1994) 503.

[11] J. von Seggern et al., Phys. Scr. T111 (2004) 118.

[12] M. Mayer et al., J. Nucl. Mater. 313-316 (2003) 429.

[13] K. Krieger et al., J. Nucl. Mater., in press. 